\title{
Understanding long-term outcomes requires prospective data collection
}

The rise of 'big data' in medical research, including genetics, should help us understand more fully the natural history and prevalence of disorders and what can be expected from our interventions, and so help us counsel our patients. Obtaining data for accreditation and revalidation purposes is a bonus, but of secondary importance. Agreement on what data need to be collected prospectively for audit, research, billing and outcomes is not easy, and is compounded by communication difficulties between clinicians and administrative coding staff. This Journal of Laryngology \& Otology issue contains an article that looks at septal surgery and nasal trauma patients, and the experience of a team who liaised closely with their coding team to identify and correct problems in communication and resulting errors. ${ }^{1}$ The problems identified are likely to be widely applicable, not just to this patient group or this institution. This study complements articles in recent issues on the efficacy of common ENT procedures ${ }^{2}$ and wide data collection on quinsy management. ${ }^{3}$

Myringoplasty outcomes nationally and in local centres has been a prominent topic in recent Journal editions. ${ }^{4,5}$ This month's issue contains an article investigating revision myringoplasty outcomes. ${ }^{6}$ It showed that revision surgery and primary surgery had similar outcomes in that particular centre, which was helpful in that hospital when counselling patients preoperatively.

Voice and swallowing problems in patients with Parkinson's disease crop up in the clinic occasionally, but the literature contains few sizeable series. This issue reports on a series of 13 patients from a tertiary voice clinic in Lewisham, which provides the basis for a strategy to help these often-neglected patients. ${ }^{7}$

Epistaxis is a major reason for acute admission to ENT wards, and the rise of anti-coagulation use in the management of cardiac disorders has exacerbated the problem. The article by Flood and colleagues in this issue examines every aspect of the evidence in relation to the use of endoscopic sphenopalatine artery ligation, ${ }^{8}$ which has become a mainstay of treatment, albeit with some variation in indications and in treatment algorithms. This analysis complements views from other recent Journal contributions on the topic. ${ }^{9,10}$ A forthcoming Journal 'virtual issue' will focus on epistaxis.

EDWARD FISHER
ROBIN YOUNGS
MUSHEER HUSSAIN
JONATHAN FISHMAN
Senior Editors

References

1 Nouraei SA, Hudovsky A, Virk J, Saleh HA. Impact of developing a multidisciplinary coded dataset standard on administrative data accuracy for septoplasty, septorhinoplasty and nasal trauma surgery. J Laryngol Otol 2017;131:341-6

2 Seymour N. How effective are common ENT operations? $J$ Laryngol Otol 2015;129:622-6

3 ENT Trainee Research Collaborative-West Midlands. National prospective cohort study of peritonsillar abscess management and outcomes: the Multicentre Audit of Quinsies study. $J$ Laryngol Otol 2016;130:768-76

4 Phillips JS, Yung MW, Nunney I. Myringoplasty outcomes in the UK. J Laryngol Otol 2015;129:860-4

5 Carr SD, Strachan DR, Raine CH. Factors affecting myringoplasty success. J Laryngol Otol 2015;129:23-6

6 Prinsley P. Results of revision myringoplasty: are they different to primary myringoplasty? J Laryngol Otol 2017;131:316-8

7 Gibbins N, Awad R, Harris S, Aymat A. The diagnosis, clinical findings and treatment options for Parkinson's disease patients attending a tertiary referral voice clinic. J Laryngol Otol 2017; 131:357-62

8 Ellinas A, Jervis P, Kenyon G, Flood LM. Endoscopic sphenopalatine artery ligation for acute idiopathic epistaxis. Does anatomical variation and a limited evidence base raise questions regarding its place in management? J Laryngol Otol 2017; 131:290-7

9 Hall AC, Blanchford H, Chatrath P, Hopkins C. A multi-centre audit of epistaxis management in England: is there a case for a national review of practice? J Laryngol Otol 2015;129:454-7

10 Fox R, Nash R, Liu ZW, Singh A. Epistaxis management: current understanding amongst junior doctors. $J$ Laryngol Otol 2016;130:252-5 